\title{
Capoeira e Identidade Cultural: um esforço de análise a partir das narrativas de mestres capoeiristas
}

\author{
Capoeira and Cultural Identity: an effort of analysis based on the narratives of \\ capoeirista masters
}

\section{Capoeira e Identidad Cultural: un esfuerzo de análisis a partir de las narrativas de maestros capoeiristas}

Elvis de Oliveira Reis ${ }^{1}$

Ana Lucy Oliveira Freire ${ }^{2}$

\begin{abstract}
RESUMO: Este trabalho é desdobramento de uma pesquisa de mestrado que se propôs a investigar como os grupos de capoeira localizados na cidade de Vitória - ES exercem a sua prática, evidenciando aspectos que promovam a consolidação das identidades culturais no território em que se encontram inseridos. A investigação apresenta como foco de estudo seis grupos de capoeira: Barraveto, Volta ao Mundo, Beribazu, Renascer, Herança Cultural e Sapeba Capoeira. Esse artigo é construído com base em entrevistas realizadas aos mestres de capoeira. Consideramos este indivíduo como o catalisador de opiniões dentro do grupo; aquele que, em limitado processo de feedback com seus discípulos, forma e informa a ideologia do grupo. O mestre exerce a função de referência e autoridade máxima, sendo respeitado e obedecido. As narrativas construídas, por meio das entrevistas, foram primordiais para entendermos e refletirmos sobre os componentes que integram a territorialidade dos grupos de capoeira, os quais colaboram para a ampliação da identidade cultural. Notamos que o principal componente desse processo são os valores transmitidos pela oralidade e pela experiência de vida dos mestres, que passam de geração a geração.
\end{abstract}

PALAVRAS-CHAVE: Capoeira. Cultura. Identidade cultural.

ABSTRACT: This article is the result of a master's research that aims to investigate how the capoeira groups located in the city of Vitória - ES, manifest their practice, highlighting aspects that promote the consolidation of cultural identities in the territory in which they are inserted. This research presents as center of study six capoeira's groups: Barravento, Volta ao mundo, Beribazu, Renascer, Henrança Cultural and Sapeba Capoeira. This article is based on interviews conducted with capoeira masters. We consider this individual as the catalyst for opinions within the group; who, in a limited process of feedback with his disciples, forms and informs the group's ideology. The master exercises the function of reference and, maximum authority, being respected and obeyed. The narratives constructed, through the interviews, were primordial to understand and reflect on the components that integrate the territoriality of capoeira groups, which collaborate for the expansion of this cultural identity. We note that the main component of this process is the values transmitted by the orality and the life experience of the masters, who pass from generation to generation.

\footnotetext{
${ }^{1}$ PPGG/UFES - Av. Fernando Ferrari, 514 - Goiabeiras, Vitória - ES, 29075-910 - elvisgeoufes@gmail.com.

${ }^{2}$ PPGG/UFES - Av. Fernando Ferrari, 514 - Goiabeiras, Vitória - ES, 29075-910 - Alucy.freire@gmail.com.
} 
KEYWORDS: Capoeira. Culture. Cultural identity.

RESUMEN: Este trabajo es el desarrollo de una investigación de maestría enfocada a los grupos de capoeira situados en distintos puntos de la ciudad de Vitoria, ejercen la practica evidenciando aspectos que promueven la consolidación de identidades culturales en el territorio que se encuentran ubicados. Esta investigación muestra como foco de estudio seis grupos de capoeira, los cuales son Barreto, Vuelta al mundo, Beribazu, Renacimiento, Herencia cultural y Sapeba Capoeira. El artículo fue creado a base de entrevistas realizadas a los maestros que imparten dicha disciplina. Consideramos a este individuo como el catalizador de opiniones dentro del grupo; el que, en el limitado proceso de retroalimentación con sus discípulos, crea e informa la ideología del grupo. El maestro ejerce la función de referencia y máxima autoridad dentro del aula, siendo respetado y obedecido. Las narraciones construidas a través de entrevistas, fueron primordiales para reconocer y reflexionar acerca de los componentes que integran la territorialidad de los grupos de capoeira, los cuales colaboran con la ampliación de la identidad cultural. Identificamos que el principal componente de dicho proceso son los valores transmitidos por la enseñanza y experiencia de vida de los maestros, que pasan de generación en generación.

PALABRAS-CLAVE: Capoeira. Cultura. Identidad cultural.

\section{INTRODUÇÃO: EXPLICITANDO O OBJETO DE ESTUDO}

A intenção ao pesquisar os grupos de capoeira da cidade de Vitória (ES) é a de contribuir de forma significativa para a valorização e o reconhecimento destes grupos que, por meio de suas vivências dentro do universo da capoeira, ajudam na construção e no fortalecimento da cultura na cidade, influenciando de maneira eficaz na consolidação das identidades culturais.

Como pesquisador da cultura afro-brasileira e, principalmente, da capoeira enquanto manifestação cultural evidenciam-se alguns desafios, que competem ao entendimento da realidade da capoeira nos dias atuais. Esses desafios estão atrelados à necessidade de melhor refletir e debater acerca da identidade cultural brasileira estabelecendo uma ligação direta com a herança africana, que muitas vezes é relegada e omitida pela sociedade.

Esse trabalho resulta da pesquisa de mestrado desenvolvida no âmbito do Programa de Pós-Graduação em Geografia da Universidade Federal do Espírito Santo, que se propôs a investigar como os grupos de capoeira localizados na cidade de Vitória - ES exercem a sua prática, evidenciando aspectos que promovam a consolidação das identidades culturais no território em que se encontram inseridos.

No primeiro ano do mestrado (2017), foi iniciada a fase de observação a partir da inserção no Grupo de Capoeira Barraventos e no Grupo de Capoeira Angola Volta ao Mundo. Por meio da vivência nesses dois grupos, foi possível estabelecer uma rede de 
contato que possibilitou realizar um breve mapeamento de outros grupos de capoeira localizados na cidade, como pode ser observado na figura 1.

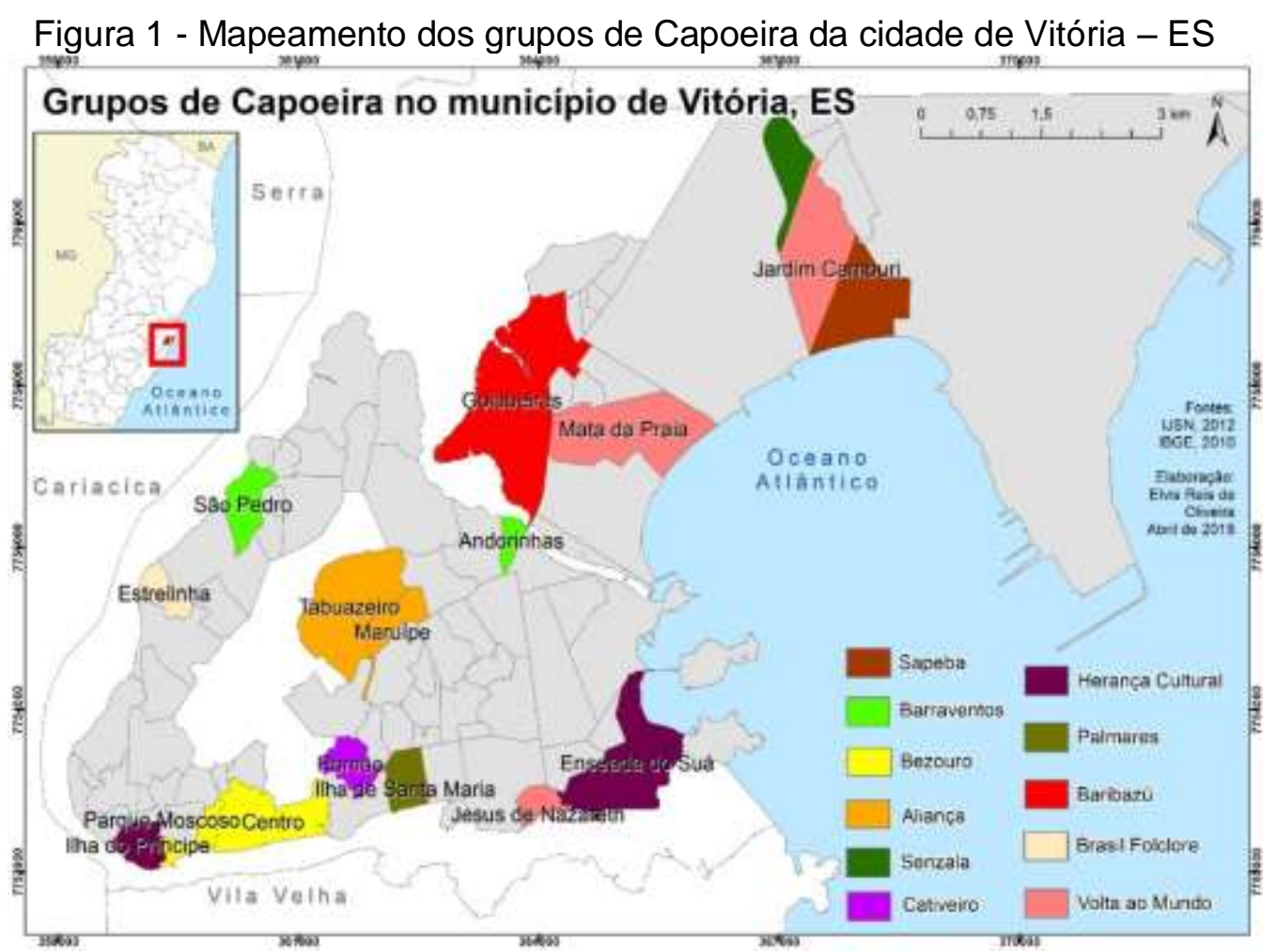

Fonte: Elaborado por Oliveira, 2018 de: IBGE (2010) e Instituto do Patrimônio Histórico e Artístico Nacional (2012).

É válido destacar que o mapa representa apenas aqueles grupos que, em algum momento durante o período de observação, foram mencionados por algum capoeirista. Todavia, o mapa atua como uma importante ferramenta na materialização da forma como a capoeira esta sendo espacializada na cidade, potencializando e oportunizando a vivência cultural em diversos bairros. A territorialização de cada grupo está intimimante ligada com as questões históricas e identitárias, contruídas ao longo da trajetória individual.

Após a realização do mapeamento, objetivando como critério de estudo a utilização de espaços públicos da cidade, estabelecemos uma amostra para melhor realização da pesquisa com seis diferentes grupos.

Sendo assim, esta investigação apresenta como delimitação espacial a cidade de Vitória - ES, tendo como foco de estudo seis grupos de capoeira que, por intermédio dos diálogos estabelecidos, aceitaram tornar-se objeto de análise por meio de entrevistas, observações e vivências. São eles: Grupo Beribazu; Grupo Renascer; Grupo Herança Cultural; Grupo Sapeba Capoeira; Grupo Barravento e o Grupo Volta ao Mundo.

Entendemos que cada grupo de capoeira tem suas particularidades, sua história e sua trajetória, tal como a história dos personagens do grupo que se configura na personificação 
dos mestres. Todavia, ao estudar as respectivas narrativas dos diferentes grupos, é possível encontrar alguns aspectos em comum, que acabam por tornarem-se eixos fundamentais para o desenvolvimento deste trabalho. Essa similaridade é evidenciada, justamente, pela realização de suas práticas em espaços ou equipamentos públicos do município de Vitória ES e pela produção de territórios efêmeros em toda cidade, uma vez que os grupos realizam suas rodas em diversos locais da capital capixaba.

Ao optar pela cidade de Vitória, consideramos que a história da capoeira, neste território, ainda não está completamente contada. Dessa forma, a realização desta pesquisa possibilita uma maior visibilidade do modo como a capoeira está se organizando no território da capital.

Para fundamentar e debater o processo histórico da capoeira, tendo como foco a relação com os espaços públicos e a consolidação da identidade cultural foi feita a análise dos seis grupos de capoeira supracitados. Segundo o mapeamento da capoeira no Espírito Santo, realizado pelo (IPHAN) Instituto do Patrimônio Histórico e Artístico Nacional (2017), a capoeira vivenciada e praticada na cidade de Vitória - ES é fruto de uma atividade que faz parte de um processo que aconteceu em todo o estado. Observou-se que a maior influência, no que se refere à estrutura da forma de expressão, é a capoeira disseminada pelo Grupo Senzala, do Rio de Janeiro, grupo que foi formado nos anos de 1960, por jovens capoeiristas cariocas.

Conforme Almeida (2008) o jogo de capoeira praticado pelo Grupo Senzala ficou conhecido como Capoeira Contemporânea, prática adotada por alguns grupos e associações de capoeira que se encontram na cidade de Vitória. Tal vertente mescla a Capoeira Angola de Mestre Pastinha e a Capoeira Regional de Mestre Bimba, incorporando em sua prática movimentos de artes marciais e ginásticas, rompendo desta forma com os modelos mais tradicionais existentes.

Todavia, anterior a todo esse processo vivenciado pela capoeira na cidade de Vitória, Filgueiras (2003), tendo como referência relatos de mestres antigos, como Mestre Odilon e Mestre Luiz Paulo, traça um caminho possível percorrido pela capoeira na cidade de Vitória, caminho este que acaba convergindo para o processo já exposto em relação à ligação com o Grupo Senzala. Segundo relato dos mestres, a capoeira em Vitória (ES) tem uma ligação direta com o samba vivenciado na cidade.

$\mathrm{Na}$ cidade de Vitória, alguns mestres se destacaram no processo histórico e cultural da capoeira capixaba, tais como: Mestre Capixaba, Mestre Caio Rezende e Mestre Luiz Paulo, em fins da década de 1970 e nos anos de 1980 esses mestres contribuíram para a ascensão da capoeira na capital capixaba, institucionalizando a capoeira, o que gerou um aumento relativo no número de participantes (FILGUEIRAS, 2003; VIEIRA, 2016). 
Foi realizado um trabalho de pesquisa de cunho empírico. Pereira (2005, p. 5), ressalta que "[...] trata-se da pesquisa desenvolvida a partir da observação direta dos fatos.", além de revisão bibliográfica sistemática sobre a temática de estudo.

Como prática metodológica foi utilizada a pesquisa qualitativa, onde "[...] o sujeitoobservador faz parte do conhecimento de fenômenos, atribuindo-Ihes um significado; sendo assim, o objeto não é neutro, possui significados e relações que os sujeitos concretos criam em suas ações" (GRUBITS; DARRAULT-HARRIS, 2004, p. 110).

Sendo assim, as discussões realizadas neste artigo também foram embasadas nas entrevistas realizadas com os mestres de capoeira dos grupos em estudo. Consideramos este indivíduo como o catalisador de opiniões dentro do grupo; aquele que, em limitado processo de feedback com seus discípulos, forma e informa a ideologia do grupo. O mestre exerce a função de referência e autoridade máxima, sendo respeitado e obedecido.

\section{CAPOEIRA E GEOGRAFIA CULTURAL: UM OLHAR INTRODUTÓRIO}

A pesquisa apresenta como foco investigativo a capoeira, porém é preciso salientar que falar de capoeira na atualidade não é uma tarefa fácil, uma vez que, com o processo de globalização, o fazer capoeira ganha uma vasta diversidade, isso levando em consideração as inúmeras formas pelas quais o jogo é praticado. Todavia, dentre as mais diversas perspectivas de análises, objetiva-se aqui adotar como base de apoio teórico os debates no âmbito da Geografia Cultural em diálogo com outras áreas do conhecimento.

Tal abordagem pode ser contextualizada no âmbito em curso hoje na Geografia Cultural, campo do conhecimento que no final do século XX passou por grandes transformações, ressurgindo com novas influências e relações baseadas no entendimento das representações e experiência do homem no espaço por meio do estudo da cultura. No Brasil, a Geografia Cultural estabeleceu maior destaque como campo de estudo após a década de 1990. Porém é preciso destacar que Claval (2002), aponta em seus estudos que desde a década de 1930 trabalhos e pesquisas com abordagem culturais já eram desenvolvidos.

Sobre os muitos trabalhos e pesquisas contemporâneos de cunho cultural desenvolvidos no Brasil, Corrêa (1995) indica que tal abordagem foi impulsionada por conta da organização espacial resultante da globalização, tornando visíveis as mais diversas formas culturais expressas no espaço. Ainda segundo o autor, tal contexto pode ter sido o fator principal para a retomada das pesquisas no campo da Geografia Cultural, sendo que, neste novo contexto, é estabelecida uma ênfase maior aos temas envolvendo as diferenças étnicas e a questão envolta dos valores. 
Em relação ao espaço onde as manifestações culturais como a capoeira são materializadas, Cosgrove (1998), ressalta que o território é percebido de diferentes modos pelos mais diversos grupos sociais que interagem e dele se apropriam, transformando-o em territórios, onde são estabelecidas territorialidades com o passar do tempo.

A territorialidade, como ressalta Serpa (2004), estabelece um sistema de relações com o que lhe é externo, ou seja, com a alteridade. Ela está impregnada de laços de identidade, que tentam de alguma forma homogeneizar esses territórios, dotá-los de uma área/superfície minimamente igualizante, seja por uma identidade territorial seja por uma fronteira definidora de alteridade.

Entender identidades em uma perspectiva que envolve a capoeira é explicitar fatores que estão diretamente ligados à cultura, tais fatos remetem à sua história de vida; à história das pessoas que formam o grupo que compartilham histórias e memórias coletivas. Visto que:

Todo grupo humano deixa transparecer, em suas manifestações culturais, características identificadoras particulares e concretas, relacionadas com sua participação na produção da sociedade, cimentando e unificando as relações por meio de sua organização, sua ideologia, seus valores e sua prática social (BRUHNS, 2000, p. 17).

É possível constatar que as pessoas, quando estão inseridas em um grupo social, como é o caso dos grupos de capoeira:

Acabam por compartilhar uma visão de mundo e formas de organização social própria, estas relações que são estabelecidas corroboram muitas vezes para a formação de um elo, estabelecido por um passado comum, e por uma mesma língua, por costumes, crenças e saberes comuns, coletivamente partilhados (INSTITUTO DO PATRIMÔNIO HISTÓRICO E ARTÍSTICO NACIONAL, 2012, p. 7).

\section{CAPOEIRA E PRÁTICA CULTURAL}

A capoeira assim como o carnaval, o samba e o futebol faz parte de um grupo de manifestações culturais da atualidade, que representam de forma emblemática a identidade cultural do nosso país. Assim, ela é considerada um patrimônio cultural pelo fato de que "[...] o patrimônio cultural de um povo é formado pelo conjunto dos saberes, fazeres, expressões, práticas e seus produtos que remetem à história, à memória e a identidade desse povo", e, segundo a mesma fonte de pesquisa, sua preservação fortalece o pertencimento de indivíduos à uma sociedade, a um grupo social ou a um determinado território, contribuindo de forma a favorecer a ampliação do exercício da cidadania e sua identificação de 
pertencimento cultural (INSTITUTO DO PATRIMÔNIO HISTÓRICO E ARTÍSTICO NACIONAL, 2012, p. 12).

Claval (2007, p. 63), por sua vez, define tal conceito como "[...] a soma dos comportamentos, dos saberes, das técnicas, dos conhecimentos e dos valores acumulados pelos indivíduos durante suas vidas" e, em outra escala, pelo conjunto dos grupos que fazem parte. Cultura é herança transmitida de uma geração a outra.

Portanto, a capoeira estudada pelo viés cultural torna-se um campo propício para o debate, isto levando em conta que na atualidade ela se configura como um conjunto de práticas que envolve música, canto, dança, jogos, rituais religiosos e movimentação corporal, aspectos que adentram o universo cultural contribuindo de forma significativa para a construção das identidades e da resistência negra no Brasil.

Dentro do contexto em debate, falar de identidades em uma perspectiva que envolve a capoeira é falar de fatores que estão diretamente ligados à cultura, fatos que se remetem à sua história de vida e das pessoas que formam o grupo, pessoas estas que compartilham memórias individuais e coletivas.

As identidades que perpassam pelo universo da capoeira são estabelecidas historicamente, levando em consideração princípios de uma identidade de resistência por manter práticas ritualísticas e religiosas negras que nasceram e se territorializaram apesar de, e por causa das desconfianças e perseguições históricas (FERRACINI, 2006).

Ainda no que diz respeito à noção de identidade, Torres (2014), escreve que se apresenta de maneira variada e complexa, isto é, as diversas identidades que possam vir a existir podem ser reforçadas continuamente por cada grupo, contribuindo possivelmente para uma construção social.

\section{IDENTIDADE CULTURAL UMA CONSTRUÇÃO SOCIAL}

Diante das situações adversas impostas ao capoeirista, a identidade cultural torna-se elemento de fortalecimento, resistência e persistência, uma vez que "[...] a capoeira integra a cultura nacional não apenas como uma forma de representação, mas também como discurso de liberdade e luta por valores com os quais nos identificamos como nação e nos afirmamos como agentes da cultura afro-brasileira" (CABRAL, 2010, p. 8).

É válido destacar que o debate em torno do conceito de identidade é um tanto complicado, uma vez que é um conceito tradicionalmente trabalhado nas Ciências Sociais, tendo uma discussão complexa, mesmo neste campo do conhecimento.

Castro (2014, p. 73) alerta que o conceito de identidade é "[...] considerado escorregadio, complexo, fugidio". Deste modo, ao trazer tal abordagem para este trabalho, não se pretende sanar lacunas apresentando respostas prontas sobre o conceito, que 
dentro do meio acadêmico é vista como tão complexa. O objetivo não é definir identidade, tampouco identidade cultural; busca-se estabelecer reflexões sobre a relação entre capoeira e a questão identitária, sobre o viés de análise das narrativas dos mestres e professores entrevistados.

Afinal, desde o final do século XIX, a capoeira é um fenômeno cultural que tem se manifestado por quase todo o território brasileiro. Tornou-se um fenômeno inusitado de representação da identidade nacional às avessas. Ou seja, carrega em si o paradoxo de ser uma arte marginalizada pelos diversos projetos nacionais e ao mesmo tempo um instrumento incomparável de divulgação da história e da cultura brasileira pelo resto do mundo. Além disso, antes mesmo de qualquer debate político ou acadêmico sobre o assunto, a capoeira já era, em sua vivência e ensino, um meio excepcional de ação afirmativa da identidade brasileira, em especial aquela produzida pela experiência do negro no Brasil (OLIVEIRA; LEAL, 2009, p. $55)$.

Haesbaert (1999, p. 6), geógrafo que nos ajuda a pensar a problemática que envolve a questão de identidade, uma vez que, em sua visão de análise, afirma "[...] não é propriamente o espaço que forma uma identidade, mas a força política e cultural dos grupos sociais que nele se reproduzem e sua capacidade de produzir uma determinada escala de identidade, territorialmente mediada".

Com base na opinião do autor citado, partimos da ideia que a construção da identidade é simbólica e social, sendo que a identidade tem sua existência atrelada à concepção de espaço produzido, que, dentro da perspectiva deste trabalho, podemos associar ao espaço vivido.

No intuito de estabelecer tal reflexão, foi questionado aos mestres dos grupos pesquisados se o grupo de capoeira contribui para a consolidação da identidade cultural daqueles que participam e como acontecia essa consolidação. As respostas foram as seguintes:

Contribui muito... para isso vamos voltar lá no passado. Antigamente o capoeirista dentro do contexto da cultura, a pessoa de olhar e falar aquele cara é capoeirista, ou seja, ele era visto como maloqueiro, bandido, marginal, ele era ridicularizado, até meados da década de 90; a capoeira era muito marginalizada. Depois das práticas junto com a Educação Física, a capoeira começou a ser mais valorizada. Então, hoje as pessoas na maioria das vezes veem o capoeirista com bons olhos; eu falo por minha vivência. Eu cheguei em 2010 aqui no estado, eu já trabalhei em várias escolas particulares [...] quando eu ando na rua, a sociedade me vê com meu abadá de capoeira, hoje não me olham com mais olhos de preconceito (MESTRE PAULISTA - Transcrição de entrevista realizada em 05/06/2018).

Eu creio que sim. Nós temos uma preocupação de estar passando todas as informações necessárias não só da capoeira, mas da história do Brasil 
porque uma anda de mãos dadas com a outra. Então, eu acho que nós conseguimos contribuir e principalmente na formação do cidadão. Sempre procurando uma boa formação para o cidadão (MESTRE NAGÔ Transcrição de entrevista realizada em 20/06/2018).

As respostas acima nos levam à associação da identidade cultural vivenciada através da formação de identidade nacional brasileira. Segundo Oliveira e Leal (2009), durante o século XIX a concepção de identidade nacional era transmitida por meio de projetos racialistas e racistas que, dentre as ações a serem implementadas, buscavam políticas de embranquecimento da população brasileira. Para esse feito, foram tomadas algumas ações: campanhas em favor da migração europeia para o país e violenta repressão às práticas culturais de matriz africana em favor de modelos culturais europeus.

As falas "vamos voltar lá no passado" e "Nós temos uma preocupação de estar passando todas as informações necessárias não só da capoeira, mas da história do Brasil porque uma anda de mãos dadas com a outra" possibilitam retomar a trajetória da capoeira frente à luta e resistência que se enquadra justamente nas repressões sofridas por ser considerada uma prática de matriz africana.

$\mathrm{Na}$ análise da narrativa, "até meados da década de 90 , a capoeira era muito marginalizada", sendo fruto de um processo histórico, a saber, entre o século XIX e início do século XX a capoeira sempre esteve associada à criminalidade. "Poucas vezes ela foi compreendida como uma prática cultural pertinente à sociedade brasileira" (OLIVEIRA; LEAL, 2009, p. 48).

Diante do que foi apresentado, podemos concluir que as expressões maloqueiro, bandido e marginal que aparecem na fala de Mestre Paulista ainda sejam herança de uma visão racista e preconceituosa que perdurou durante muito tempo na sociedade.

Entretanto, a transição e o reconhecimento aconteceram e a capoeira, tanto em Vitória, quanto em todo o Brasil, vivencia um reconhecimento que foi fruto de muito trabalho por toda a comunidade capoeirista "[...] quando eu ando na rua, a sociedade me ver com meu abadá de capoeira, hoje não me olham com mais olhos de preconceito" (MESTRE PAULISTA - Transcrição de entrevista realizada em 05/06/2018).

Fica claro, portanto, que a formação e consolidação da identidade cultural é fruto do processo histórico, em que o presente e o passado se condicionam mutuamente (SAQUET; BRISKIEVICZ, 2009). Tal fato se torna, ainda mais, importante ao fundamentarmos as respostas acima, a partir de Claval (2001, p. 179):

A identidade é construída a partir da interiorização de uma tradição, são afinidades que são estabelecidas transmitindo às pessoas que as vivenciam o sentimento de pertencer a determinados grupos sociais. A identidade pode basear-se na "ideia de uma descendência comum, de uma história 
assumida em conjunto ou de um espaço com o qual o grupo assume elos" $[\ldots]$.

Sendo assim, o fato dos mestres compartilharem a história da capoeira atrelada à história do Brasil auxilia na interiorização da tradição e ancestralidade, que pode culminar na criação de afinidade com quem está ouvindo, podendo consolidar a identidade cultural. Ao usar o termo "pode", entendemos que a formação e consolidação da identidade cultural é uma ação individual, em que cada sujeito vivencia e experimenta de uma maneira diferente, em um determinado período. Outra resposta extraída das narrativas dos mestres foi a seguinte:

Eu acredito que forma, pois procuramos fazer uma apresentação de capoeira a partir do fenômeno da análise síntese, é apresentado o ritmo do berimbau, o berimbau com toda a sua bateria, depois com a música com vários ritmos, depois o movimento feito isolado, o movimento de dois a dois, a canto; até chegar à roda que é símbolo maior, isso constrói através do grupo, da música o movimento da capoeira, e dentro das lutas. Uma das formas de apropriação é pela apreciação estética e a identidade ela se cria inicialmente pelos órgãos do sentido, pela observação, pela audição, pela visão você vai criando uma apreciação identitária, só que tem um problema, a identidade pode ser uma identidade de resistência uma identidade de projeto ou uma identidade legitimadora, que são identidades completamente diferentes, então depende como a pessoa recebe isso a partir da sua formação que você já tem, mas eu acredito que constrói uma identidade e o grupo tem essa proposta (MESTRE FÁBIO - Transcrição de entrevista realizada em 07/07/2018).

A narrativa acima, trazida por Mestre Fábio que, além de mestre de capoeira é também professor do Centro de Educação Física da Universidade Federal do Espírito Santo, evidencia que sua vivência e metodologia desenvolvida no dia a dia da capoeira são direcionadas por conceitos científicos, tendo em vista que a própria capoeira se faz presente em suas pesquisas e práticas docentes desenvolvidas no meio acadêmico.

Nesse sentido, ao embasar sua fala em Castells (1999), entende-se que, ao utilizar como ferramenta o fenômeno da análise síntese, o Mestre Fábio possibilita que os alunos vivenciem a capoeira em sua totalidade, acompanhando passo a passo todo o processo que envolve a multidimensionalidade expressada através da capoeira, sendo que esta análise terá como desembocadura a roda de capoeira, símbolo maior de representatividade dessa manifestação.

A roda existe há dezenas de anos na trajetória da capoeira e trata-se do ritual sagrado capaz de expressar sinteticamente parte do universo da capoeira. Desta forma, a roda seria o lugar ideal onde a identidade cultural dos praticantes pode vir a emergir, isso levando em consideração que: 
Pensar a roda é pensar o ritual, o ciclo, princípio, meio e fim, território do devir corporificado na forma circular, lugar gerador de sentidos, abrigo de universos simbólicos repleto de significados. A roda de capoeira é movimento incessante, eterno recomeço forma viva que guarda a ancestralidade de memórias simbólicas de culturas diversas (GUIMARÃES, 2013, p. 171).

Ao dizer que "[...] uma das formas de apropriação é pela apreciação estética e a identidade ela se cria inicialmente pelos órgãos do sentido, pela observação, pela audição, pela visão você vai criando uma apreciação identitária", sendo assim no processo de constituição da capoeira enquanto manifestação cultural compreende-se que o momento que melhor possibilita a formação de espaços que conduz à apreciação identitária, conforme mencionada pelo Mestre Fábio, seria justamente a roda de capoeira, uma vez que:

"A partir da formação corpórea do círculo, todas as relações de pertencimento se fazem presentes, todos os olhares são vistos, todos os movimentos são vividos, numa dinâmica coletiva harmonizada pelo ritmo do berimbau e pelo canto uníssono do coro que responde às cantigas" (GUIMARÃES, 2013, p. 173).

Em relação às formas de identidades manifestadas entendemos que, como já mencionado, manifestam-se de maneira individual em cada sujeito, sendo que, "[...] determinadas identidades [...] manifestam-se em função das condições espaço - temporais em que o grupo está inserido" (HAESBAERT, 1999, p. 175). A resposta a seguir possibilita uma reflexão envolvendo a consolidação da identidade cultural por meio de um aspecto diretamente ligado à capoeira.

A capoeira tem uma essência de brasilidade tão grande. A capoeira traz em si, nas cantigas, nos gestos motores, em tudo. Na história do Brasil e da história da nossa ancestralidade, de quem passou antes da gente. A gente traz junto com a gente isso num movimento de capoeira, num gesto, num olhar, na música. No que a música fala, não só no ritmo, mas no que as letras contam. Então a pessoa passa a conhecer um pouco mais do Brasil, do Espírito Santo, de Vitória, de cultura de outros estados também através da capoeira. Uma fonte riquíssima de cultura, principalmente cultura afrobrasileira, mas também indígena, por que não? Tantas palavras na capoeira são indígenas, a própria palavra capoeira tem também significado indígena. Então, eu acho que tem a brasilidade total aí, a pessoa entra na capoeira, se ela pensava em outros países em morar na Europa, como teve um aluno que falou outro dia que pensava em ir embora daqui, morar em outro país; quando conheceu a capoeira passou amar o país e não quis mais sair daqui de Vitória (MESTRE SAPEBA - Transcrição de entrevista realizada em 02/08/2018).

O comentário feito por Mestre Sapeba enfatiza outra ferramenta fundamental da capoeira, que contribui para consolidação da identidade cultural: as músicas na capoeira. Diversas cantigas, ladainhas, chulas e corridos são de domínio público; outras são de 
autoria própria dos integrantes do grupo que buscam nas letras exaltar seu grupo, a história do seu mestre e a cultura local.

Em geral, por meio das cantigas de capoeira, a consolidação da identidade pode ser construída e fundamentada nas homenagens aos grandes mestres, bem como na história dos heróis da cultura negra, ou até mesmo ao relacionar acontecimentos marcantes da cidade, do estado ou do país. Então, a pessoa passa a conhecer um pouco mais do Brasil, do Espírito Santo, de Vitória e de cultura de outros estados também através da capoeira.

\section{CONCLUSÕES}

A capoeira, como manifestação cultural brasileira, contribui na consolidação da identidade cultural como forma simbólica e de resistência no território, a partir dos valores simbólicos determinando, assim, diferentes práticas. Reconhecida como patrimônio por ser algo valorizado por determinada comunidade, passou a ser classificada como um bem cultural, de ordem material e imaterial.

A convivência com os capoeiristas e as conversas com os mestres ajudaram na construção de conhecimentos. Assim, observamos que o conhecimento produzido pelos grupos sociais estava pautado na centralidade desses indivíduos e no contexto social inserido.

Durante o processo de investigação, reconhecemos os mestres de capoeira e seus discípulos como sujeitos ativos das relações estabelecidas e construídas nas aulas, nas rodas ou nos eventos. A pesquisa partiu do princípio de que a capoeira age como um elemento agregador de valores significativos. Esses valores são fundamentais para a formação da territorialidade, que corrobora para a consolidação da identidade cultural. Portanto, na realização da pesquisa, percebemos que a prática da capoeira se consolida em uma ação educacional, pois ela atua na construção e no fortalecimento da identidade cultural.

As narrativas construídas, por meio das entrevistas, foram primordiais para entendermos e refletirmos sobre os componentes que integram a territorialidade dos grupos de capoeira, os quais colaboram para a ampliação da identidade cultural. Notamos que o principal componente desse processo são os valores transmitidos pela oralidade e pela experiência de vida dos mestres, que passam de geração a geração. 


\section{REFERÊNCIAS}

ALMEIDA, J. A. de. A reflexividade nos discursos identitários da capoeira. 2008. $151 \mathrm{f}$. Dissertação (Mestrado em Educação Física) - Universidade Federal do Espírito Santo, ES, Vitória, 2008.

BRUHNS, H. Futebol, carnaval e capoeira: entre as gingas do corpo brasileiro. Campinas: Papirus, 2000.

CABRAL, M. G. Pensando a identidade cultural ao som do berimbau. Pontos de Interrogação: Revista de Crítica Cultural, Alagoinhas, BA, v. 1, p. 701-710, 2010.

CASTELLS, M. O poder da identidade. São Paulo: Paz e Terra, 1999.

CASTRO, J. R. B. As questões identitárias e as especificidades culturais da Bahia expressas na literatura e na musicalidade: um olhar geográfico. Geo Textos Salvador, BA, v. 10, n. 1, p. 105-126, 2014.

CLAVAL, P. A geografia cultural. Florianópolis: UFSC, 2001.

CLAVAL, P. A geografia cultural. Florianópolis: UFSC, 2007.

CLAVAL, P. A volta da cultura na geografia. Mercator, Fortaleza, CE, v. 1, n. 1, p. 19-28, 2002.

CORRÊA, R. L. A dimensão cultural do espaço: alguns conceitos. Espaço e Cultura, Rio de Janeiro, RJ, v. 1, p. 1-21, out. 1995.

COSGROVE, D. A geografia está em toda parte: cultura e simbolismo nas paisagens humanas. In: CORRÊA, R. L.; ROSENDAHL, Z. (org.). Paisagem, tempo e cultura. Rio de Janeiro: EDUERJ, 1998. p. 92 - 123.

FERRACINI, R. A. L. O espetáculo na praça: territorialidade, identidade e rituais negros na cidade de Goiás. 2006. Dissertação (Mestrado em Geografia) - Universidade Federal de Goiás, GO, Goiânia, 2006.

FILGUEIRAS, J. P. Tá tudo dominado: a institucionalização da capoeira. Caderno Textos e Debates, Florianópolis, SC, v. 8, p. 23-41, 2003.

GRUBITS, S.; DARRAULT-HARRIS, I. Método qualitativo: um importante caminho no aprofundamento das investigações. In: GRUBITS, S.; NORIEGA, J. A. V. (org.). Método qualitativo: epidemiologia, complementaridades e campos de aplicação. São Paulo, SP: Vetor, 2004. p. 15- 27.

GUIMARÃES, A. A. Capoeira: a roda, o jogo, o ritual. In: BARRETO, M. A. S. C.; ANDRADE, P. G. R.; CUNHA JUNIOR, H. A.; RODRIGUES, A. (org.). Africanidade(s) e afrodescendencia(s): perspectivas para a formação de professores. Vitória, ES: EDUFES, 2013. v. 1, p. 169-180.

HAESBAERT, R. Identidades territoriais. In: ROSENDAHL, Z.; CORRÊA, R. L. (org.).

Manifestações da cultura no espaço. Rio de Janeiro: EDUERJ, 1999. p. 169-190.

IBGE. Cidades. Vitória, Espírito Santo. 2010. Disponível em:

https://cidades.ibge.gov.br/brasil/es/panorama. Acesso em: 1 dez. 2018.

INSTITUTO DO PATRIMÔNIO HISTÓRICO E ARTÍSTICO NACIONAL - IPHAN.

Mapeamento da capoeira no Espírito Santo. Vitória, ES: IPHAN, 2017.

INSTITUTO DO PATRIMÔNIO HISTÓRICO E ARTÍSTICO NACIONAL - IPHAN. Patrimônio cultural imaterial: para saber mais. Brasília, DF: IPHAN, 2012. Disponível em:

http://portal.iphan.gov.br/uploads/publicacao/cartilha_1_parasabermais_web.pdf. Acesso em: 5 abr. 2018. 
INSTITUTO JONES DOS SANTOS NEVES - IJSN. Plano de desenvolvimento urbano integrado. Região Metropolitana da Grande Vitória. Vitória, ES, 2012. (Diagnóstico Integrado, v. 2). Disponível em:

http://www.ijsn.es.gov.br/component/attachments/download/6301. Acesso em: 1 dez. 2018.

OLIVEIRA, J. P.; LEAL, L. A. P. Capoeira, identidade e gênero: ensaios sobre a história social da capoeira no Brasil. Salvador: EDUFBA, 2009.

PEREIRA, P. A. O que é pesquisa em educação? São Paulo: Paulus, 2005.

SAQUET, M. A.; BRISKIEVICZ, M. Territorialidade e identidade: um patrimônio no desenvolvimento territorial. Caderno Prudentino de Geografia, Presidente Prudente, SP, v. 1, n. 31, p. 3-16, 2009.

SERPA, A. S. P. Espaço público e acessibilidade: notas para uma abordagem geográfica. GEOUSP: Espaço e Tempo, São Paulo, SP, n. 15, p. 21-37, 2004.

TORRES, F. do C. Espaço público: apropriação e direito ao uso: a territorialidade das rodas de capoeira em Brasília (Distrito Federal). 2014. 263 f. Dissertação (Mestrado em Geografia) - Instituto de Ciências Humanas, Universidade de Brasília, Brasília, 2014.

VIEIRA, C. H. A inteligência da cultura popular: uma etnografia da capoeira. Vitória, ES: Leitura Fina, 2016.

Recebido: fevereiro de 2019. Aceito: maio de 2019. 